\title{
Türk ve Alman Turistleri Tatile İten ve Çeken Faktörlerin Analizi ${ }^{1}$
}

\author{
(Araştırma Makalesi)
}

\section{Analysis of Factors Driving and Attracting Turkish and German Tourists Doi: 10.29023/alanyaakademik.814273}

\author{
Salih TELLIOĞLU \\ Alanya Alaaddin Keykubat Üniversitesi, ALTSO Turizm MYO \\ slhtellioglu@gmail.com \\ Orcid No: 0000-0001-6510-110X
}

How to cite this article: Tellioğlu, S. (2021). "Türk ve Alman Turistleri Tatile Itten ve Çeken Faktörlerin Analizi”, Alanya Akademik Bakış, 5(1), Sayfa No. 287-299.

\section{Anahtar kelimeler: \\ Seyahat motivasyonu, İtme faktörleri, Çekme faktörleri, Kültürel farklılık, Destinasyon özellikleri}

Makale Geliş Tarihi: 21.10.2020

Kabul Tarihi:

25.11.2020

Keywords:

Dollar, Foreign

Exchange, BIST100,

Stock Exchange, Hedge Mechanism

\section{ÖZET}

Turizmin giderek daha geniş bir alana yayılması ile birlikte kültürel farklilıkları anlamak ve bu bağlamda hedef pazarlar belirlemek turistik ülkeler için önemli hale gelmiştir. Bu farklılıklar destinasyon yöneticileri için önemli olmasının yanında araştırmacıların da ilgisini çeken bir konu olmuştur. Yapılan araştırmalar ile destinasyon özelliklerinin hangi pazar segmentine daha uygun olduğu tespit edilerek destinasyonlara hedef pazarlarını belirleyebilme imkanı sağlanmaktadır. Bu çalı̧̧mada Türk ve Alman turistlerden 198 adet anket toplanmıs ve her iki milliyetin seyahat motivasyonlar itme ve çekme teorisi kullanılarak analiz edilmiştir. İtme ve çekme motivasyon öğelerinin boyutlarını belirlemek için faktör analizi kullanılmış ve faktör analizi sonuçlarına göre de dört itme ve beş çekme faktör boyutu ortaya çıkmıştır. Hem itme hem de çekme faktörlerde Alman turistlerin önem ortalamalarının Türk turistlere göre daha yüksek olduğu bulunmuştur. Ayrıca itme ve çekme faktörlerinin milliyetlere göre önemli ölçüde farklılaş̧tı̆̆ belirlenmiştir.

\begin{abstract}
With the spread of tourism to a wider area, understanding cultural differences and determining target markets in this context has become important for touristic countries. To identify these differences is not only important for destination managers, but also has attracted the attention of researchers. Through the studies, it can be determined the destination characteristics are more suitable for which market segment. This enables destinations to determine their target markets. In this study, 198 questionnaires were collected from Turkish and German tourists and the travel motivations of both nationalities were analyzed using the push and pull motivional theory.. Factor analysis was used to determine the dimensions of push and pull motivation elements, and according to the results of the factor analysis, four push factor and five pull factor dimensions were revealed. It has been found that the average importance of German tourists is higher than Turkish tourists in both push and pull
\end{abstract}

\footnotetext{
${ }^{1}$ Bu çalışma, Uluslararası Sosyal Bilimler ve Eğitim Bilimleri Sempozyumunda sözlü bildiri olarak sunulmuştur
} 


\section{GİRIŞ}

Turizm, dünyanın en hızlı büyüyen ekonomik sektörlerinden biri haline gelmek için sürekli bir büyüme ve çeşitlilik içerisindedir. Birleşmiş Milletler Dünya Turizm Örgütü'nün verilerinde 2019 yılında dünya genelinde 1,5 milyar kişinin tatil amacıyla seyahat ettiği ve bu sayının bir önceki yıldan 54 milyon daha fazla olduğu yer almaktadır (UNWTO, 2020). Turizm faaliyet gösterdiği ülkelerde önemli bir istihdam kaynağ 1 oluşturmak ile birlikte bu ülkelere döviz geliri sağlayarak ülkelerin ekonomisine önemli katkılar sağlamaktadır (Bahar ve Bozkurt, 2010: 256). Turizm endüstrisinin giderek büyümesi ile birlikte turizm, turistik ülkelerde sosyo-ekonomik ilerleme için kilit bir itici güç haline gelmiştir (UNWTO, 2019).

Turizmin daha geniş bir alana yayılması destinasyon sayısının ve destinasyonlar arasında rekabetin giderek artmasına neden olmaktadır. Bu bağlamda, destinasyonların ve işletmelerin rekabet avantajı elde etmek için yüksek kaliteli hizmet ve tatmin edici turizm deneyimleri sağlamaları gerekmektedir (De Nisco vd, 2015: 72). Ayrıca küreselleşme ile müşteri istek ve ihtiyaçları da değişmekte (Özer ve Günaydın, 2010: 128) ve bu değişim tüketici istek ve beklentilerinin önem kazanmasına neden olmaktadır. Bu nedenle, destinasyonların ve işletmelerin faaliyetlerini tüketicilerin beklenti ve ihtiyaçlarına göre sürdürmesi zorunluluğu ortaya çıkmıştır (Öztürk ve Seyhan, 2005; Özkara, 2007; Civelek, 2016). Turistlerin beklenti ve ihtiyaçları ile birlikte onları seyahat etmeye motive eden faktörler onların demografik özelliklerine ve milliyetlerine göre farklılık göstermektedir (Armstrong vd.,, 1997: 181). Bu tür farklılıklardan dolayı destinasyon yöneticileri her bir müşteri grubunun özelliklerini belirleyerek, turizm pazarlarını bölümlere ayırmalı ve her pazar için uygun pazarlama stratejileri geliştirmelidir (Kozak, 2002: 221).

$\mathrm{Bu}$ araştırmanın amacı Türk ve Alman turistleri seyahatlere motive eden faktörlerin belirlenmesi ve bu faktörlerin milliyetlere göre karşılaştırılmasıdır. Türk ve Alman turistlerin seyahat motivasyonları arasında fark olup olmadığını analiz etmek için itme ve çekme teorisi kullanılmıştır. Farklı kültürleri temsil eden turistleri seyahat etmeye motive eden faktörlerin belirlenmesi onların ziyaret ettiği destinasyonlar için oldukça önemlidir. $\mathrm{Bu}$ araştırma kapsamına dahil olan Alman turistler özellikle İspanya, İtalya, Avusturya ve Türkiye için her zaman önemli bir turizm pazarı olmuştur (Munoz, 2007: 13). Türk turistler ise Bulgaristan, Gürcistan ve Yunanistan için önemli bir pazardır (TÜRSAB, 2019). Bunun yanında Türk turistlerin iç turizme sağladığı katkı her yıl giderek artmakta ve Türk turistler yabancı turistlere göre daha istikrarlı bir turizm talebi oluşturmaktadır (Tellioğlu ve Tekin, 2016: 505). Bu çalışmadan elde edilen bulgular Türk ve Alman turistleri hedef pazar olarak gören destinasyonlara önemli ölçüde katkı sağlayacaktır.

\section{KAVRAMSAL ÇERÇEVE}

Destinasyon, bir yerin kendi markası altında tüketilen turizm ürün ve hizmetlerinin birleşimini ifade etmektedir (Buhalis, 2000). Diğer taraftan, bir destinasyonu başarılı bir şekilde yönetmek için turistlerin seyahat memnuniyetini en üst düzeye çıkarmak çok önemlidir (Yoon ve Uysal, 2005: 47). Bunun için de turistleri seyahat etmeye motive eden faktörleri ve bu faktörler arasındaki ilişkiyi iyi bir şekilde anlamak gerekir (Goodrich, 1977; akt, Baloğlu ve Uysal, 1996: 32). Çünkü motivasyon turistleri seyahat etmeye yönlendiren 
etkin bir faktör olmasının yanında (Bright, 2008) turist davranışlarını da anlayan en önemli psikolojik etkenlerden biridir (Khuong ve Ha, 2014: 490).

\subsection{Seyahat Motivasyonu}

Motivasyon kavramının merkezinde ihtiyaç kavramı yer almaktadır. Çünkü ihtiyaçlar davranışları uyandıran ve motive eden güç olarak görülmektedir (Mansfeld ve Pizam, 1999). Turizm literatüründe turistlerin motivasyonlarını ölçmek amacıyla birçok araştırma yapılmış ve farklı teoriler öne sürülmüştür (Witt ve Wright, 1992; Fodness, 1994; Kozak, 2002; Pearce ve Lee, 2005).

Iso-Ahola (1982), turizm motivasyonunu açıklamak için sosyal ve psikolojik faktörlere odaklanmış ve arama ile kaçış bileşenlerinin turistlerin turizm motivasyonunu etkileyen faktörler olduğunu ileri sürmüştür. Teoriye göre arama bileşeni belirli bir grup bireyin daha çok önem verdiği motivasyon faktörü olsa da kaçış bileşeni daha etkili bir motive edici güçtür. Pearce (1993) tarafından geliştirilen ve Maslow İhtiyaçlar Hiyerarşisi üzerine inşa edilen çok amaçlı bir model olan Seyahat Kariyer Merdiveni (TCL) ise yaygın olarak kullanılan modellerden bir tanesidir. Bu modele göre; fizyolojik, güvenlik, ilişki, gelişim ve tatmin olmak üzere beş farklı ihtiyaç seviyesi aracılığıyla turistlerin motivasyonları anlaşılabilecektir. Dann (1977) ise turist motivasyonunu açıklamada itme ve çekme faktörlerinin önemli olduğunu öne sürmüştür. Bu çalışmanın amacına uygun olarak burada belirtilen teorilerden itme ve çekme faktörleri teorisi ele alınacaktır. Bundan dolayı çalışmanın bundan sonraki aşamasında konunun daha iyi anlaşılması için itme ve çekme faktörleri detaylı bir şekilde açıklanacaktır.

\subsection{1 İtme-Çekme Faktörleri}

Turistlerin seyahat motivasyonunu açıklayan birçok teori olmasına rağmen en çok kullanılan yöntemlerden birisi Dann (1977) tarafından önerilen itme-çekme faktörleridir. Bu teoriye göre itme faktörleri, turistlerin seyahat planlaması yapmaya yönelik içsel dürtülerini ölçmekteyken, çekme faktörleri ise destinasyonların turistleri çeken özelliklerini ölçmektedir. Diğer bir ifadeyle itme faktörleri turistleri tatil yapmaya motive ederken çekme faktörleri turistleri bir destinasyona seyahat etmeye çekmektedir (Wong vd, 2017: 396-397). Bu bağlamda itme faktörü tatile çıkma arzusunu, çekme faktörü ise destinasyon seçimini açıklamaktadır (Crompton, 1979: 410). İtme-çekme faktörleri son y1llarda turistlerin destinasyonlara yönelik seyahat motivasyonunu ölçmek için yapılan birçok araştırmada araştırmacılar tarafindan tercih edilen bir yöntem olmuştur (Mohammed ve Som, 2010; Nikjoo ve Ketabi, 2015; Yousefi ve Marzuki, 2015; Wong, Musa ve Taha, 2017; Karasakal ve Dursun, 2018; Antana ve Premaswari, 2018; Katsikari vd, 2020).

İtme ve çekme motivasyon faktörlerinin birlikte değerlendirilmesi pazarları segmentlere ayırmak (Baloğlu ve Uysal, 1996: 38) ve ürünlerin hangi pazara uygun olduğunu tespit edebilmek açısından oldukça önemlidir (Oh, vd., 1995: 136). Bu bağlamda, destinasyon kaynakları ile turist motivasyonlarının birbiri ile eşleştiği pazarlara odaklanmak destinasyonlara önemli faydalar sağlayacaktır (Kozak, 2002: 222).

Turistleri tatil yapmaya iten kendi içsel faktörleri olduğu kadar dışsal faktörler de söz konusudur (Crompton, 1979: 410). Dışsal faktörler, destinasyonların özellikleri ve turistlerin bunlardan algıladıkları fayda değerleri açısından oldukça önemlidir. Destinasyonların özellikleri destinasyonlara göre değişebilmekle birlikte genel olarak; iklim, ekoloji, kültür, 
mimari, oteller, catering, ulaşım, eğlence, maliyet vb. kriterlerini içermektedir (Kozak, 2002: 222).

\section{METODOLOJI}

Bu araştırmanın verileri 2019 yılı Eylül ve Ekim aylarında 198 Türk ve Alman turiste anket çalışması uygulanarak toplanmıştır. Çalışmada Türk ve Alman turistleri tatil yapmaya motive eden itme ve çekme faktörleri tespit edebilmek için Yousefi ve Marzuki (2015)'in geliştirdiği ölçekten faydalanılmıştır. Bu ölçekte 18 itme ve 18 çekme faktörlerinden oluşan toplam 36 soru yer almaktadır. Araştırmada kullanılan anket üç bölümden oluşmaktadır. İlk bölümde katılımcılara ait demografik bilgilere ve seyahat özelliklerine yer verilmiştir. İkinci bölümde 18 sorudan oluşan itme faktörlerine yer verilmiştir. Üçüncü bölümde ise yine 18 sorudan oluşan çekme faktörlerine yer verilmiştir. Araştırmada 7'li likert tipi ölçek kullanılmıştır. 7'li likert ölçeğinde derecelendirmeler şöyle ifade edilmiştir: (1) Oldukça önemsiz, (2) Çok önemsiz, (3) Az önemsiz, (4) Ne önemli ne de önemsiz, (5) Az önemli, (6) Çok önemli, (7) Oldukça önemli.

Araştırmadan elden edilen bulguları analiz etmek için Sosyal Bilimler için İstatistik Paketi (SPSS) kullanılmıştır. Araştırmada yer alan itme ve çekme motivasyon öğelerinin altında yatan boyutları belirlemek için faktör analizi yapılmıştır. Ayrıca itme ve çekme faktörlerinin Türk ve Alman turistlere göre farklılık gösterip göstermediğini ölçmek için de bağımsız t testi uygulanmıştır.

\subsection{Araştırmanın Bulguları}

Araştırmaya katılanların \% 52.5'i Türk, \% 47.5'i ise Alman'dır. \% 53'ü kadın ve \% 47'si erkektir. \% 49'u bekar, \% 51'i evlidir. Araştırmaya katılanların çoğunluğu (\% 57.6) 18-34 yaş aralığındadır ve yine önemli çoğunluğu lise (\% 32.8) ve lisans (\% 41.9) mezunudur. Katılıcıların büyük çoğunluğu yılda en az bir kez tatile gittiğini ve genellikle aileleri ile gittiği tespit edilmiştir. Ayrıca tatillerini çoğunlukla web sayfası üzerinden aldıklarını belirtmişlerdir.

Tablo 1. Katılımcılara ait bilgiler

\begin{tabular}{|l|c|c|l|c|c|}
\hline Milliyet & $\mathbf{n}$ & $\boldsymbol{\%}$ & Yaş Aralı̆̆ & $\mathbf{n}$ & $\mathbf{\%}$ \\
\hline Türk & 104 & 52.5 & $18-34$ yaş arası & 114 & 57.6 \\
\hline Alman & 94 & 47.5 & $35-49$ yaş arası & 73 & 36.9 \\
\hline Cinsiyet & $\mathbf{n}$ & $\mathbf{\%}$ & $50-64$ yaş arası & 10 & 5.1 \\
\hline Kadın & 105 & 53.0 & 65 ve üstü & 1 & .5 \\
\hline Erkek & 93 & 47.0 & Ĕgitim Durumu & $\mathbf{n}$ & $\%$ \\
\hline Medeni Durum & $\mathbf{n}$ & $\mathbf{\%}$ & İlk Öğretim Mezunu & 7 & 3.5 \\
\hline Bekâr & 97 & 49.0 & Lise Mezunu & 65 & 32.8 \\
\hline
\end{tabular}


ALANYA AKADEMİK BAKIŞ DERGİSİ 5/1 (2021)

\begin{tabular}{|l|c|c|l|c|c|}
\hline Evli & 101 & 51.0 & Ön Lisans Mezunu & 4 & 2.0 \\
\hline Tatile ne sıkıkla gidersiniz & $\mathbf{n}$ & $\%$ & Lisans Mezunu & 83 & 41.9 \\
\hline Hiç gitmedim & 6 & 3.0 & Lisans Üstü Mezunu & 39 & 19.7 \\
\hline Birkaç yılda bir giderim & 64 & 32.3 & $\begin{array}{l}\text { Tatil Satın alma işlemini } \\
\text { hangisi ile yaparsınız }\end{array}$ & $\mathbf{n}$ & $\%$ \\
\hline Yılda en az bir kez & 99 & 50.0 & Acente Bürosu & 29 & 14.6 \\
\hline Yılda iki kez ve üzeri & 29 & 14.6 & Acente Web Sayfası & 43 & 21.7 \\
\hline Tatile kiminle gidersiniz & $\mathbf{n}$ & $\%$ & Acente Çağrı Merkezi & 20 & 10.1 \\
\hline Yalnız & 12 & 6.1 & Otel Web sayfası & 45 & 22.7 \\
\hline Ailemle & 128 & 64.6 & Otel Çağrı Merkezi & 20 & 10.1 \\
\hline Arkadaşlarımla & 52 & 26.3 & Diğer & 35 & 17.7 \\
\hline
\end{tabular}

\subsection{1. İtme Faktörlerinin Faktör Analizi}

Araştırmada yer alan itme faktörlerin güvenilirlik analizi için Cronbach's Alpha kullanılmıştır. Analiz sonuçlarına göre itme faktörlerin Cronbach's Alpha .815 'dir ve kabul edilebilir düzeyin $(\alpha=.60)$ üzerinde olduğu tespit edilmiştir. 18 maddeden oluşan ölçeğe uygulanan güvenirlik testi sonucunda bir önermenin güvenirliliği düşürdüğü saptanmış ve o önerme araştırmaya dahil edilmemiştir. Ölçeğin KMO (Kaiser-Meyer- Olkin Measure of Sampling Adequacy) değeri 0.798 (>0.6'dan) bulunmuş ve faktör analizi için uygun olduğu tespit edilmiştir.

\begin{tabular}{lll}
\hline KMO & .798 & \\
\hline Bartlett's Test of Sphericity & 999.971 & sig:0,00 \\
\hline Güvenirlik katsayısı & .815 & \\
\hline
\end{tabular}

İtme motivasyon öğelerinin altında yatan boyutları belirlemek için 17 itme faktörüne açımlayıcı faktör analizi uygulanmış ve birden büyük öz değerler ile 4 faktör (farklı yerler görmek, dinlenme ve rahatlama, tatil deneyimi, farklı kültür) oluşmuştur. Bu faktörlere göre açıklanan toplam varyans \% 58.59'dur. Tablo 2'de faktör analizi sonuçlarına yer verilmiştir.

Tablo 2. Faktör Analizi / İtme Faktörleri

\begin{tabular}{|l|c|c|c|}
\hline İtme Faktörleri & $\begin{array}{l}\text { Faktör } \\
\text { yükleri }\end{array}$ & Öz Değerler & Varyans \% \\
\hline Farklı Yerler Görmek & & 5.24 & 30.87 \\
\hline Daha önce görmediğim farklı şeyler görmek & 0.758 & & \\
\hline Hayalimi ve merakımı gidermek & 0.642 & & \\
\hline Farklı bir çevre/ortam görmek & 0.619 & & \\
\hline
\end{tabular}




\begin{tabular}{|c|c|c|c|}
\hline Yeni ve heyecan verici bir yerler görmek & 0.591 & & \\
\hline Dinlenme ve Rahatlama & & 1.87 & 11.02 \\
\hline Fiziksel olarak dinlenip rahatlamak & 0.837 & & \\
\hline Günlük hayatın stresinden kaçmak için & 0.809 & & \\
\hline Rutin işlerden uzaklaşmak & 0.603 & & \\
\hline Eğlenmek ve mutlu olmak & 0.529 & & \\
\hline Tatil Deneyimi & & 1.55 & 9.11 \\
\hline Arkadaşlarımın daha önce gittiği yerleri görmek & 0.912 & & \\
\hline $\begin{array}{l}\text { Tatilden döndükten sonra çevrem } \\
\text { deneyimimi paylaşabilmek }\end{array}$ & 0.746 & & \\
\hline Birçok insanın değer verdiği ve takdir ettiği yerleri & 0.608 & & \\
\hline Her zaman gittiğim yerlere tekrar gitmek & 0.562 & & \\
\hline Yeni insanlarla tanışmak & 0.494 & & \\
\hline Farklı Kültür & & 1.29 & 7.59 \\
\hline Yabancı bir ülke hakkındaki bilgi ve tecrübelerimi & 0.876 & & \\
\hline $\begin{array}{l}\text { Farklı ülkelerdeki insanların nasıl yaşadıklarını ve } \\
\text { yaşam biçimlerini görmek }\end{array}$ & 0.766 & & \\
\hline Kendi kültürümden farklı kültürleri görmek & 0.722 & & \\
\hline Daha önce ziyaret etmediğim bir ülkeyi görmek & 0.524 & & \\
\hline
\end{tabular}

\subsection{2. Çekme Faktörlerinin Faktör Analizi}

Araştırmada yer alan çekici faktörlerin güvenilirlik analizi için Cronbach's Alpha kullanılmıştır. Analiz sonuçlarına göre çekici faktörlerin Cronbach's Alpha ,789'dur ve kabul edilebilir düzeyin $(\alpha=, 60)$ üzerindedir. 18 maddeden oluşan ölçeğe uygulanan güvenirlik testi sonucunda bir önermenin güvenirliliği düşürdüğü saptanmış ve o önerme araştırmaya dahil edilmemiştir. Ölçeğin KMO (Kaiser-Meyer- Olkin Measure of Sampling Adequacy) değeri 0,749 (>0,6'dan) bulunmuş ve faktör analizi için uygun olduğu tespit edilmiştir.

\begin{tabular}{lll}
\hline KMO & .749 & \\
\hline Bartlett's Test of Sphericity & 846.561 & sig: 0,00 \\
\hline Güvenirlik katsayısı & .789 & \\
\hline
\end{tabular}

Çekme motivasyon öğelerinin altında yatan boyutları belirlemek için 17 çekme faktörüne açımlayıcı faktör analizi uygulanmış ve birden büyük öz değerler ile 5 faktör (eğlence ve alışveriş, yakın ve güvenli yerler, kültürel özellikler, ucuzluk ve plaj ve gezmek/görmek) oluşmuştur. Bu faktörlere göre açıklanan toplam varyans \% 58.48'dir. Tablo 3'de faktör analizi sonuçları yer verilmiştir. Araştırma kapsamında bazı ifadelerin faktör yükleri 0,50'nin altında çıkmış olsa da 0.30 sınır olarak belirlenmiştir. Yaşlıoğlu (2017), örneklem sayısı arttıkça kabul edilebilecek yük değeri 0.3 'e kadar kabul edilebileceğini belirtmiştir. Hair vd. 
(1995) ise bu yükleri $\pm 0.30=$ minimum, $\pm 0.40=$ önemli ve $\pm .50=$ anlamlı olarak sınıflandırmıştır.

Tablo 3. Faktör Analizi / Çekme Faktörleri

\begin{tabular}{|l|c|c|c|}
\hline Çekme Faktörleri & $\begin{array}{c}\text { Faktör } \\
\text { yükleri }\end{array}$ & $\begin{array}{c}\text { Öz } \\
\text { Değerler }\end{array}$ & Varyans \% \\
\hline Eğlence ve alışveriş & & 4.18 & 24.58 \\
\hline Festival ve çeşitli etkinliklerin olduğu yerlere gitmek & 0.839 & & \\
\hline Çeşitli alışveriş yerlerine sahip olan yerlere gitmek & 0.705 & & \\
\hline Çeşitli cazibe merkezlerine sahip yerlere gitmek & 0.598 & & \\
\hline Yakın ve Güvenli Yerler & & 1.91 & 11.22 \\
\hline Temiz ve düzenli yerlere gitmek & 0.862 & & \\
\hline Güvenli ve emniyetli yerlere gitmek & 0.858 & & \\
\hline Uygun iklim şartlarına sahip olan yerlere gitmek & 0.56 & & \\
\hline Kaliteli turistik alanlara sahip yerlere gitmek & 0.549 & & \\
\hline Seyahat mesafesi kı destinasyonlara gitmek & 0.381 & & \\
\hline Kültürel Özellikler & & 1.48 & 8.68 \\
\hline Kültürel ve tarihi yerleri görmek & 0.808 & & \\
\hline Doğal güzelliklere sahip olan yerleri görmek & 0.755 & & \\
\hline Birçok farklı kültüre sahip olan yerleri görmek & 0.551 & & \\
\hline Farklı yemekleri tatmak & 0.365 & & \\
\hline Ucuzluk ve Plaj & & 1.33 & 7.79 \\
\hline Fiyatı ucuz olan yerlere gitmek & 0.553 & & \\
\hline $\begin{array}{l}\text { Deniz ve plajlara sahip olan yerlere gitmek } \\
\text { Gezmek / Görmek }\end{array}$ & 0.541 & & \\
\hline Yerel halk ile sıcak ve samimi ilişkilerin kurulabileceği & 0.683 & & \\
\hline Kutsal yerleri görmek & 0.497 & & \\
\hline $\begin{array}{l}\text { Seyahat ve gezi ile ilgili bilgilere ulaşabileceğim yerlere } \\
\text { Stan-1. }\end{array}$ & 0.402 & & \\
\hline
\end{tabular}

\subsection{3. İtme Motivasyon Faktörleri için T Testi Analizi}

Araştırmaya katılan Türk ve Alman turistlerin itme motivasyon özelliklerine göre aritmetik ortalamalarını belirleyebilmek ve anlamlı farklılıklar olup olmadığını tespit edebilmek için bağımsız bir örneklem t testi uygulanmıştır. Sonuçlar Tablo 4'te yer almaktadır.

Tablo 4. İtme Faktörler için T Testi

\begin{tabular}{|c|c|c|c|c|c|c|}
\hline \multirow[b]{2}{*}{ İtme Faktörleri } & \multicolumn{2}{|c|}{ Türk } & \multicolumn{2}{|c|}{ Alman } & & \\
\hline & $\mathbf{n}$ & $\overline{\mathbf{X}}$ & $\mathbf{n}$ & $\overline{\mathbf{X}}$ & $\mathbf{t}$ & $\mathbf{p}$ \\
\hline Dinlenme ve Rahatlama & 104 & 6.27 & 94 & 6.18 & & \\
\hline
\end{tabular}


TELLİOĞLU

\begin{tabular}{|c|c|c|c|c|c|c|}
\hline Günlük hayatın stresinden kaçmak için & 104 & 6.3 & 94 & 5.96 & 2.36 & 0.019 \\
\hline Rutin işlerden uzaklaşmak & 104 & 5.94 & 94 & 6.11 & -0.916 & 0.361 \\
\hline Fiziksel olarak dinlenip rahatlamak & 104 & 6.37 & 94 & 5.94 & 2.861 & 0.005 \\
\hline Eğlenmek ve mutlu olmak & 104 & 6.47 & 94 & 6.72 & -2.008 & 0.046 \\
\hline Farklı Kültür & 104 & 5.35 & 94 & 5.83 & & \\
\hline Yabancı bir ülke hakkındaki bilgi ve tecrübelerimi geliştirmek & 104 & 5.22 & 94 & 5.67 & -2.218 & 0.028 \\
\hline Kendi kültürümden farklı kültürleri görmek & 104 & 5.65 & 94 & 6.21 & -3.147 & 0.002 \\
\hline Farklı ülkelerdeki insanların nasıl yaşadıklarını ve yaşam biçimlerini görmek & 104 & 5.27 & 94 & 5.59 & -1.447 & 0.15 \\
\hline Daha önce ziyaret etmediğim bir ülkeyi görmek & 104 & 5.26 & 94 & 5.85 & 1.371 & 0.172 \\
\hline Farklı Çevre & 104 & 6.09 & 94 & 6 & & \\
\hline Yeni ve heyecan verici bir yerler görmek & 104 & 6.25 & 94 & 5.87 & 2.174 & 0.031 \\
\hline Daha önce görmediğim farklı şeyler görmek & 104 & 6.29 & 94 & 6.07 & 1.371 & 0.172 \\
\hline Farklı bir çevre/ortam görmek & 104 & 6.01 & 94 & 6.07 & -0.389 & 0.698 \\
\hline Hayalimi ve merakımı gidermek & 104 & 5.82 & 94 & 5.99 & -0.909 & 0.364 \\
\hline Tatil Deneyimi & 104 & 4.64 & 94 & 4.59 & & \\
\hline Yeni insanlarla tanışmak & 104 & 4.92 & 94 & 4.74 & 0.708 & 0.48 \\
\hline Arkadaşlarımın daha önce gittiği yerleri görmek & 104 & 4.08 & 94 & 4.12 & -0.136 & 0.892 \\
\hline Birçok insanın değer verdiği ve takdir ettiği yerleri görmek & 104 & 5.63 & 94 & 5.51 & 0.635 & 0.526 \\
\hline Her zaman gittiğim yerlere tekrar gitmek & 104 & 4.68 & 94 & 4.1 & 2.656 & 0.009 \\
\hline Tatilden döndükten sonra çevrem ile tatil deneyimimi paylaşabilmek & 104 & 3.96 & 94 & 4.46 & -1.752 & 0.081 \\
\hline
\end{tabular}

İtme faktörlerinin özellikleri incelendiğinde Türk ve Alman turistler için en önemli özelliğin "eğlenmek ve mutlu olmak" olduğu görülmektedir. Türkler için en önemsiz itme özelliği "Tatilden döndükten sonra çevrem ile tatil deneyimimi paylaşabilmek" iken Almanlar için "Her zaman gittiğim yerlere tekrar gitmek"tir. İtme faktör analizleri üzerinde Türk ve Alman turistleri tatile motive eden en önemli faktör boyutlarının dinlenme ve rahatlamaya yönelik özellikler olduğunu belirtmek gerekir. Ayrıca birçok itme özellikleri arasında Türk ve Alman turistlere göre anlamlı farklılıklar olduğu tespit edilmiştir $(\mathrm{p}<0.05)$. Bunlar arasında en önemli fark "Kendi kültürümden farklı kültürleri görmek" seçeneğinde bulunmuştur. Anlamlı farklılıkların yer aldığı diğer motivasyon öğeleri ise; "Günlük hayatın stresinden kaçmak, Fiziksel olarak dinlenip rahatlamak, Eğlenmek ve mutlu olmak, Yabancı bir ülke hakkındaki bilgi ve tecrübelerimi geliştirmek, Kendi kültürümden farklı kültürleri görmek, Yeni ve heyecan verici bir yerler görmek, Her zaman gittiğim yerlere tekrar gitmek ve Tatilden döndükten sonra çevrem ile tatil deneyimimi paylaşabilmek"tir. 


\subsection{4. Çekme Motivasyon Öğeleri için Faktör Analizi}

Araştırmaya katılan Türk ve Alman turistlerin çekme motivasyon özelliklerinin aritmetik ortalamalarını belirleyebilmek ve anlamlı farklılıklar olup olmadığını tespit edebilmek için bağımsız bir örneklem t testi uygulanmıştır. Sonuçlar Tablo 5'de yer almaktadır.

Tablo 5. Çekme Faktörleri için T Testi

\begin{tabular}{|c|c|c|c|c|c|c|}
\hline \multirow[b]{2}{*}{ Çekme Faktörleri } & \multicolumn{2}{|c|}{ Türk } & \multicolumn{2}{|c|}{ Alman } & \multirow[b]{2}{*}{$\mathbf{t}$} & \multirow[b]{2}{*}{$\mathbf{p}$} \\
\hline & $\mathbf{n}$ & $\overline{\mathbf{X}}$ & $\mathbf{n}$ & $\overline{\mathbf{X}}$ & & \\
\hline Kültür & 104 & 5.89 & 94 & $\overline{6}$ & & \\
\hline Birçok farklı kültüre sahip olan yerleri görmek & 104 & 5.42 & 94 & 6.04 & -3.39 & 0.001 \\
\hline Kültürel ve tarihi yerleri görmek & 104 & 5.87 & 94 & 5.72 & 0.748 & 0.456 \\
\hline Farklı yemekleri tatmak & 104 & 5.34 & 94 & 5.89 & -2.937 & 0.004 \\
\hline Doğal güzelliklere sahip olan yerleri görmek & 104 & 6.38 & 94 & 6.23 & 0.969 & 0.334 \\
\hline Yakın ve Güvenli Yerler & 104 & 6.1 & 94 & 6.04 & & \\
\hline Seyahat mesafesi kısa destinasyonlara gitmek & 104 & 5.57 & 94 & 5.05 & 2.394 & 0.018 \\
\hline Kaliteli turistik alanlara sahip yerlere gitmek & 104 & 5.53 & 94 & 5.29 & 1.027 & 0.305 \\
\hline Güvenli ve emniyetli yerlere gitmek & 104 & 6.43 & 94 & 6.41 & 0.117 & 0.907 \\
\hline Temiz ve düzenli yerlere gitmek & 104 & 6.4 & 94 & 6.53 & -0.931 & 0.353 \\
\hline Uygun iklim şartlarına sahip olan yerlere gitmek & 104 & 6.02 & 94 & 6.17 & -0.824 & 0.411 \\
\hline Eğlence ve alışveriș & 104 & 4.97 & 94 & 5.25 & & \\
\hline Çeşitli cazibe merkezlerine sahip yerlere gitmek & 104 & 5.19 & 94 & 5.41 & -0.971 & 0.333 \\
\hline Festival ve çeşitli etkinliklerin olduğu yerlere gitmek & 104 & 4.83 & 94 & 5.3 & -1.917 & $\mathbf{0 . 0 5 7}$ \\
\hline Çeşitli alışveriş yerlerine sahip olan yerlere gitmek & 104 & 4.37 & 94 & 5 & -2.479 & 0.014 \\
\hline Ucuzluk ve Plaj & 104 & 5.67 & 94 & 5.6 & & \\
\hline Fiyatı ucuz olan yerlere gitmek & 104 & 5.79 & 94 & 5.13 & 3.845 & $\mathbf{0}$ \\
\hline Deniz ve plajlara sahip olan yerlere gitmek & 104 & 5.56 & 94 & 6.06 & -2.426 & 0.016 \\
\hline Gezmek / Görmek & 104 & 5.28 & 94 & 5.32 & & \\
\hline Kutsal yerleri görmek & 104 & 5.14 & 94 & 4.55 & 2.414 & 0.017 \\
\hline Yerel halk ile sıcak ve samimi ilişkilerin kurulabileceği yerlere gitmek & 104 & 5.21 & 94 & 5.71 & -2.464 & 0.015 \\
\hline Seyahat ve gezi ile ilgili bilgilere ulaşabileceğim yerlere gitmek & 104 & 5.49 & 94 & 5.69 & -1.092 & 0.276 \\
\hline
\end{tabular}

Çekme faktör özellikleri ile ilgili yapılan analiz sonuçlarına göre ise hem Türk turistler hem de Alman turistler için en önemli çekme faktörleri "Güvenli ve emniyetli yerlere gitmek" ve "Temiz ve düzenli yerlere gitmek" özelliğidir. Türk turistler için en önemsiz çekme özelliği "Çeşitli alışveriş yerlerine sahip olan yerlere gitmek " iken Alman turistler için "Kutsal yerleri görmek"tir. Ayrıca birçok çekime faktörü arasında Türk ve Alman turistlere göre 
anlamlı farkl1lıklar olduğu tespit edilmiştir $(\mathrm{p}<0.05)$. Bunlar arasında en önemli fark "Fiyatı ucuz olan yerlere gitmek" motivasyon özelliğinde bulunulmuştur. Anlamlı farklılıkların yer aldığı diğer motivasyon öğeleri ise; "Birçok farklı kültüre sahip olan yerleri görmek, Farklı yemekleri tatmak, Doğal güzelliklere sahip olan yerleri görmek, Seyahat mesafesi kısa destinasyonlara gitmek, Festival ve çeşitli etkinliklerin olduğu yerlere gitmek, Çeşitli alışveriş yerlerine sahip olan yerlere gitmek, Deniz ve plajlara sahip olan yerlere gitmek, Kutsal yerleri görmek ve Yerel halk ile sıcak ve samimi ilişkilerin kurulabileceği yerlere gitmek”tir.

\section{SONUÇ VE TARTIŞMA}

Turizmin giderek daha geniş bir alana yayılması destinasyonlar arası rekabetin de artmasına neden olmuştur. Destinasyonların etkili bir şekilde rekabet edebilmesi için ziyaretçilere harika deneyimler ve mükemmel değerler sunması gerekir. Destinasyonlar, ziyaretçilere en yüksek kalitede deneyim sağlamak için rekabet ettikçe destinasyon yönetimi daha önemli hale gelmektedir (UNWTO, 2007). Bir destinasyonu iyi bir şekilde yönetebilmek için turistleri seyahat etmeye motive eden faktörleri ve bu faktörler arasındaki ilişkiyi çok iyi anlamak gerekir (Goodrich, 1977; akt,Baloğlu ve Uysal, 1996: 32).

Destinasyon kriterleri üzerinden sosyo-demoğrafik özellikler bağlamında yapılan çalışmalar destinasyon yöneticilerine hangi pazar segmentlerini hedefleyeceğini, hangi segmentlere hizmet vereceğini ve hangilerinin göz ardı edileceği hakkında bilgiler vermektedir (Bright, 2008: 260; Smith vd., 2010: 19). Yapılan birçok çalışmada farklı milliyetlere sahip turistlerin tatil özelliklerinin ve seyahat motivasyonlarının farklılık gösterdiği tespit edilmiş̧ir (Kozak, 2002: 221; Wong vd., 2017 ). Bu çalışmada da itme-çekme teorisi kullanılarak Türk ve Alman turistleri seyahat etmeye yönelik motivasyonların farklılık gösterip göstermediği araştırılmıştır.

Araştırma kapsamında turistlerin seyahat motivasyonunu ölçmek amaciyla 17 itme ve 17 çekme faktörü analiz edilmiştir. Araştırma sonucunda elde edilen bulgulara göre itme ve çekme faktörlerinin milliyetlere göre önemli ölçüde farklılaştığı belirlenmiştir. Ayrıca hem itme ve çekme faktörlerinden on tanesinde Alman turistlerin önem ortalamalarının Türk turistlere göre daha yüksek olduğu, kalan yedi faktörlerde ise Türk turistlerin önem ortalamaları Alman turistlere göre daha yüksek olduğu bulunmuştur. Alman turistlerin seyahat motivasyonun Türk turistlere göre daha yüksek çıkmasının en önemli nedeni Alman turistlerin tatil yapma alışkanlığının Türk turistlere göre daha fazla olmasındandır. Alman turistler dünya turizm sektöründe önemli bir yere sahip olmakla birlikte özellikle İspanya, İtalya, Avusturya ve Türkiye için önemli bir turizm pazarı olarak görülmektedir (Munoz, 2007: 13).

Türk ve Alman turistler için en önemli itme faktörünün "eğlenmek ve mutlu olmak" olduğu görülmektedir. İtme faktörleri arasında Türk ve Alman turistleri tatile motive eden en önemli etkenlerin dinlenme ve rahatlamaya yönelik özellikler olduğunu belirtmek gerekir. Ancak Yousefi ve Marzuki (2015)'nin çalışmasında ise itme faktörleri arasında "Dinlenme ve Rahatlama” önem ortalaması en düşük faktör boyutu olarak görülmektedir. Bu sonuç turistlerin demografik özelliklerine, seyahat türü ve amacına göre motivasyon özelliklerinin farklılaştı̆ıını göstermektedir. Türk ve Alman turistler için en önemli çekme faktörleri ise "Güvenli ve emniyetli yerlere gitmek"tir. Her iki milliyet için de en önemli çekme faktör boyutunun "Yakın ve Güvenli Yerlere Gitmek" olduğu görülmektedir. Prayag ve Ryan (2011)'da Alman turistlerin diğer milliyetlere göre destinasyon güvenliğine daha fazla önem 
verdiğini bulmuştur. Öztürk ve Şimşek (2013) ise Türk turistlerin diğer milliyetlere göre güvenlik unsuruna daha çok önem verdiğini, güvenli olmayan destinasyonlara seyahat etmediği sonucuna ulaşmıştır. Aynı çalışmada turistlerin gelir seviyesi arttıkça güvenlik önem derecesinin de orantılı olarak arttı̆̆ tespit edilmiştir.

\section{KAYNAKÇA}

ANTARA, M. \& PREMASWARI, Y. A. (2018). "Push and Pull Factors of Tourists Visit the Tourism Destination of Bali", Indonesia. Journal of Tourism and Hospitality Management, 6(1), 112-120.

ARMSTRONG, R. W., MOK, C., GO, F., \& CHAN, G. (1997). "The Importance of CrossCultural Expectations in the Measurement of Service Quality Perceptions in the Hotel Industry". International Journal of Hospitality Management, 16(2), 181-190.

BAHAR, O. \& BOKURT, K. (2010). “Gelişmekte Olan Ülkelerde Turizm-Ekonomik Büyüme İlişkisi: Dinamik Panel Veri Analiz”. Anatolia Turizm Araştırmaları Dergisi, 21,2, 255-265.

BALOGLU, S. \& UYSAL, M. (1996). "Market Segments of Push and Pull Motivations: A Canonical Correlation Approach”. Int. J. Contemp. Hosp. Manag. 1996(8), 32-38.

BRIGHT, A. D. (2008). Motivations, Attitudes, and Beliefs. H. Oh, and A. Pizam (Edit.), Handbook of Hospitality Marketing Management, 239-265,Oxford, UK: Elsevier.

BUHALIS, D. (2000). "Marketing the Competitive Destination of the Future". Tourism Management, 21 (2000), 97-116

CIVELEK, A. (2016). "Konaklama İşletmelerinde Müşteri İlişkileri Yönetiminin İşletme Performansına Etkisi: 5 Yıldızlı Oteller Üzerine Bir Uygulama”. Selçuk Üniversitesi Sosyal Bilimler Meslek Yüksekokulu Dergisi, 19 (2), 233-253.

CROMPTON, J. L. (1979). "Motivations For Pleasure Vacation". Annals of Tourism Research, 6(4), 408-424.

DANN, G. (1977). “Anomie, Ego-enhancement and Tourism”. Annals of Tourism Research, $4(4), 184 \mathrm{e} 194$.

DE NISCO, A., RIVIEZZO, A., \& NAPOLITANO, M. R. (2015). “An ImportancePerformance analysis of tourist satisfaction at destination level: evidence from Campania (Italy)”. European Journal of Tourism Research, 10, 64 - 75.

FODNESS, D. (1994). "Measuring tourist motivation”. Annals of Tourism Research, 21(3), 555-581.

GIRISH P. \& CHRIS R. (2011). “The Relationship Between the 'Push' and 'Pull' Factors of a Tourist Destination: The Role of Nationality - An Analytical Qualitative Research Approach", Current Issues in Tourism, 14(2), 121-143, DOI: $10.1080 / 13683501003623802$

GOODRICH, J.N. (1977). "Benefit Bundle Analysis: An Empirical Study of International Travellers", Journal of Travel Research, 26(2), 6-9. 
HAIR J, ANDERSON RE, TATHAM RL, \& BLACK WC. (1995). Multivariate data analysis. 4th ed. New Jersey: Prentice- Hall Inc; 1995

ISO-AHOLA, S. E.(1982). “Toward A Social Psychological Theory of Tourism Motivation: A Rejoinder". Annals of Tourism Research, 9(2), 256-262.

KARASAKAL, S. \& DURSUN, A. (2018). "Destinasyona Yönelik İtici ve Çekici Faktörler: Bir Literatür İncelemesi”. Journal of Recreation and Tourism Research, 5(1), 23-37

KATSIKARI, C., HATZITHOMAS, L., FOTIADIS, T. \& FOLINAS, D. (2020). "Push and Pull Travel Motivation: Segmentation of the Greek Market for Social Media Marketing in Tourism”. Sustainability, 2020(12), 1-18.

KHUONG, M. N. \& HA, H. T. T. (2014). "The Influences of Push and Pull Factors on the International Leisure Tourists' Return Intention to Ho Chi Minh City, Vietnam - A Mediation Analysis of Destination Satisfaction". International Journal of Trade, Economics and Finance, 5(6), 490-496.

KOZAK, M. (2002). "Comparative Analysis of Tourist Motivations by Nationality and Destinations”. Tourism Management 23 (2002), 221-232.

MANSFELD, Y. \& PIZAM, A. (1999). Consumer Behaviour in Travel and Tourism. New York: An Imprint of The Haworth Press.

MOHAMMAD, B. \& SOM A.(2010). "An Analysis of Push and Pull Travel Motivations of Foreign Tourists to Jordan”. International Journal of Business and Management, 5(12), 41-50.

MUNOZ, T. G. (2007). “German demand for tourism in Spain”. Tourism Management, 28 (2007), 12-22

NIKJOO, A.H. \& KETABI, M. (2015) "The Role of Push and Pull Factors in the Way Tourists Choose Their Destination". Anatolia, 26(4), 588-597, DOI: 10.1080/13032917.2015.1041145

OH, H.M., UYSAL, M. \& WEAVER P., A. (1995). "Product Bundles and Market Segments Based on Travel Motivations: A Canonical Correlation Approach". Int. J. Hosp. Manag. 1995(14), 123-137.

ÖZER, Ö. \& GÜNAYDIN, Y. (2010). “Otel İşletmelerinde Müşteri Memnuniyeti ve Müşteri Sadakati İlişkisi: Dört Yıldızlı Otel İşletmelerinde Bir Uygulama”. Dokuz Eylül Üniversitesi İşletme Fakültesi Dergisi, 11(2), 127-154.

ÖZTÜRK, Y. \& SEYHAN, K. (2005). "Measuring service quality in hotel operations by servqual method”. Anatolia: Turizm Araştırmaları Dergisi, 16(2), 170-182.

PRAYAG, G. \& RYAN, C. (2011) “The relationship between the 'push' and 'pull' factors of a tourist destination: the role of nationality - an analytical qualitative research approach", Current Issues in Tourism, 14:2, 121-143, DOI: $10.1080 / 13683501003623802$ 
PEARCE, P. L. (1993). Fundamentals of Tourist Motivation. In D. Pearce, \& R. Butler (Eds.), Tourism Research: Critiques and challenges (pp. 85e105). London: Routledge and Kegan Paul

PEARCE PL, \& LEE U-I. (2005). "Developing the Travel Career Approach to Tourist Motivation". Journal of Travel Research, 43(3), 226-237. doi: $10.1177 / 0047287504272020$

SYLVIA S, CAROL C \& ROBERT A. M. (2010) "Influence of Push and Pull Motivations on Satisfaction and Behavioral Intentions within a Culinary Tourism Event", Journal of Quality Assurance in Hospitality \& Tourism, 11(1), 17-35, DOI: $10.1080 / 15280080903520584$

TELLİĞLU, S. \& TEKİN, M. (2016). “Türkiye’de İç Turizm Hareketlerinin İncelenmesi”. Akademik Sosyal Araştırmalar Dergisi, 4(32), 488-507.

TÜRSAB (2019). Türkiye'den çıkan yurttaşlar nereye gidiyor. https://www.tursab.org.tr/istatistikler/yurtici-seyahat-pazari Erişim: 28.09.2020

UNWTO (2020). World Tourism Barometer and Statistical Annex, January 2020.

UNWTO (2019). Why Tourism ? https://www.unwto.org/why-tourism Erişim: 01.10.2020

UNWTO. (2007). A Practical Guide to Tourism Destination Management. World Tourism Organization..

WONG, B. K. M., MUSA, G. \& TAHA, A. Z. (2017). "Malaysia My Second Home: The Influence of Push and Pull Motivations on Satisfaction”. Tourism Management, 61 (2017), 394-410.

WITT, C. A. \& WRIGHT, P. L. (1992). “Tourist Motivation: Life After Maslow”. Choice and Demand in Tourism, 33-35

YAŞLIOĞLU, M. M. (2017). "Sosyal Bilimlerde Faktör Analizi ve Geçerlilik: Keşfedici ve Doğrulayıcı Faktör Analizlerinin Kullanılması". İstanbul Üniversitesi İşletme Fakültesi Dergisi, 46(2017), 74-85.

YOON, Y. \& UYSAL, M. (2005). "An Examination of the Effects of Motivation and Satisfaction on Destination Loyalty: a Structural Model". Tourism Management 26 (2005), 45-56

YOUSEFI, M. \& MARZUKI, A. (2015) “An Analysis of Push and Pull Motivational Factors of International Tourists to Penang, Malaysia", International Journal of Hospitality \& Tourism Administration, 16:1, 40-56, DOI: 10.1080/15256480.2015.991987 